Review article

\title{
Estimates of malnutrition associated with chronic kidney disease patients globally and its contrast with India: An evidence based systematic review and meta-analysis
}

\author{
Ishfaq Rashid ${ }^{\mathrm{a}}$, Aamir Bashir ${ }^{\mathrm{a}}$, Pramil Tiwari ${ }^{\mathrm{a}, *}$, Sanjay D’Cruz ${ }^{\mathrm{b}}$, Shivani Jaswal ${ }^{\mathrm{c}}$ \\ ${ }^{a}$ Department of Pharmacy Practice, National Institute of Pharmaceutical Education and Research, Mohali, Punjab, 160062 India \\ ${ }^{\mathrm{b}}$ Department of General Medicine, Government Medical College and Hospital, Chandigarh, India \\ ${ }^{\mathrm{c}}$ Department of Biochemistry, Government Medical College and Hospital, Chandigarh India
}

\section{A R T I C L E I N F O}

\section{Keywords:}

Chronic kidney disease

Dialysis

Geography

Malnutrition

Prevalence

Random effect model

\begin{abstract}
A B S T R A C T
Background: Malnutrition is one of the most serious complications of chronic kidney disease due to its devastating consequences in terms of quality of life, morbidity, hospitalization and mortality. This study aims to evaluate the prevalence of malnutrition among chronic kidney disease patients globally and its contrast with India. Methods: Articles reporting the prevalence of malnutrition associated with CKD patients were retrieved from PubMed/Medline, ScienceDirect, Cochrane library \& Google scholar. The quality assessment of studies was performed by using Newcastle-Ottawa scale. The pooled prevalence was reported with effect size considering the random effect model using comprehensive meta-analysis version 2.0.

Results: The results from 61 observational studies containing 21119 patients are presented. The global prevalence of malnutrition associated with CKD was found to be $42.7 \%$. The prevalence of malnutrition in peritoneal dialysis group was found to be $(45.3 \%, 95 \% \mathrm{CI} ; 29.5-62.1)$ higher as compared to hemodialysis group (43.1\%, 95\% CI; 32.2-54.7) followed by non-dialysis group (38.5\%, 95\% CI; 24.0-55.3). The prevalence of malnutrition in India was found to be $56.7 \%$ (95\% CI: 42.4-70.0\%). Males were predominantly affected with malnutrition as compared to females. The prevalence in India was reported to be higher as compared to all the included countries, except Mexico and Jordan.

Conclusions: Globally, India occupies the highest share of prevalence studies followed by Brazil. The geographical stratification of results revealed that the highest prevalence of malnutrition was observed in India except Mexico and Jordan. Given the high prevalence of malnutrition among CKD patients, evaluation of interventions for malnutrition with patient centered outcomes are warranted.
\end{abstract}

\section{Introduction}

Chronic kidney disease is a global public health problem. Patients suffering from chronic kidney disease have various comorbidities such as hypertension, diabetes, inflammation etc. It is also reported that chronic kidney disease is associated with a high economic cost to health systems and is an independent risk factor for cardiovascular disease.

Nutrition is profoundly found to be altered in chronic kidney disease as the result of deranged renal regulation of systemic homeostasis. ${ }^{1}$ Malnutrition is one of the most serious complications of chronic kidney disease. Its consequences, particularly for patients on hemodialysis as well as on continuous ambulatory peritoneal dialysis, are devastating in terms of quality of life, morbidity, hospitalization and mortality. ${ }^{2,3}$

Earlier, nutritional status was usually assessed by measuring anthropometric variables. These anthropometric variables were measured by different methods including dual-energy X-ray absorptiometry or bioelectrical impedance analysis, and total body nitrogen. Total body nitrogen quantifies the body's protein content and is considered the gold standard for assessing the nutritional status of patients with end stage renal disease.

Currently, nutritional status is assessed by employing noninvasive techniques which involve using validated tools or questionnaire. Different tools available in the open domain are; subjective global assessment tool (SGA), malnutrition inflammation score (MIS), mini nutritional assessment tool (MNA), and subjective global nutritional

\footnotetext{
* Corresponding author.

E-mail addresses: ishfaqrashid139@gmail.com (I. Rashid), waniaamir025@gmail.com (A. Bashir), ptiwari@niper.ac.in (P. Tiwari), sanjaydcruz@gmail.com (S. D’Cruz), shivanirishiraj@yahoo.co.in (S. Jaswal).
} 


\begin{tabular}{|c|c|}
\hline \multicolumn{2}{|c|}{ Abbreviations } \\
\hline CMA & Comprehensive Meta-Analysis \\
\hline CKD & Chronic Kidney Disease \\
\hline ESRD & End Stage Renal Disease \\
\hline MIS & Malnutrition Inflammation Score \\
\hline MNA & Mini Nutritional Assessment tool \\
\hline NOS & Newcastle Ottawa Scale \\
\hline RevMan & Review Manager \\
\hline PRISMA & $\begin{array}{l}\text { Preferred Reporting Items for Systematic Reviews and } \\
\text { Meta-Analyses }\end{array}$ \\
\hline PROSPEF & $\begin{array}{l}\text { The International Prospective Register of Systematic } \\
\text { Reviews }\end{array}$ \\
\hline SGA & Subjective Global Assessment tool \\
\hline SGNA & Subjective Global Nutritional Assessment \\
\hline
\end{tabular}

assessment (SGNA). The best method to evaluate nutritional status includes a composite approach using both anthropometric measurements and nutritional assessment tools.

The management of chronic kidney disease complications are more challenging as it goes unnoticed. Early screening and identification is an important determinant for the timely management of complications like malnutrition associated with chronic kidney disease.

This work is an attempt to evaluate the pooled prevalence of malnutrition among chronic kidney disease patients globally and its contrast with India. Pooled prevalence was also estimated with respect to patient type (hemodialysis, peritoneal-dialysis and non-dialysis), region (country-wise breakup), assessment tool and gender.

\section{Methods}

\subsection{Search strategy and selection criteria}

This systematic review and meta-analysis was conducted in accordance with the Meta-Analysis of Observational Studies in Epidemiology guidelines $^{4}$ and the protocol has been published (PROSPERO: CRD42021226344) in Prospero registry for systematic review and Meta-analysis. The search strategy was discussed with an expert for optimum inclusion sensitivity. A systematic literature search was conducted by using following repositories: PubMed, Cochrane library, Google scholar, science direct databases to identify the articles published during last 30 years (1990-2020). The manual search was also performed to find out the relevant articles.

The electronic search on PubMed/Medline database was performed using advanced filters and Medical Science Heading (MeSH) terms: ("Prevalence" [MeSH Terms] OR "Prevalence studies" [Title/Abstract] OR "Prevalence Study" [Title/Abstract] OR "studies prevalence" [Title/ Abstract] OR "study prevalence" [Title/Abstract]) AND ("Malnutrition" [MeSH Terms] OR "undernutrition" [Title/Abstract] OR "Malnourishment" [Title/Abstract] OR "overnutrition" [MeSH Terms]) AND ("renal insufficiency, chronic" [MeSH Terms] OR "Chronic Renal Insufficiencies" [Title/Abstract] OR "Chronic Kidney Diseases" [Title/ Abstract] OR "Chronic Kidney Insufficiency" [Title/Abstract] OR "renal disease chronic" [Title/Abstract] OR "disease chronic renal" [Title/ Abstract]). [Supplementary file A]

The relevant articles were screened in full text to check for eligibility criteria. Cross-referencing from all the selected articles were done to check for other similar articles.

\subsection{Inclusion and exclusion criteria}

All the observational studies published between 1990 and 2020 from any study setting population, with the age group of 18 years or more having chronic kidney disease associated malnutrition reported by using any nutritional assessment tool and/or anthropometric measurements were included. The studies with unresolved discrepancies in data or the date repeated in different studies or the nutritional status were not reported or having language barrier were excluded from the study.

\subsection{Study outcome}

The study outcomes were reported as effect size, which is the pooled prevalence of malnutrition among chronic kidney disease patients globally along with India based on patient type (non-dialysis, hemodialysis, peritoneal-dialysis, \& unspecified dialysis), region (country wise break-up), assessment tool and gender.

\subsection{Data extraction and quality assessment}

Initially, the articles were screened for eligibility and the data extraction based on journal, title, abstract, and publication year was done by two authors [IR and AB] independently. The authors [PT, SD \& $\mathrm{SJ}$ ] were engaged in resolving the discrepancies in the study and data (if any). The articles were then reviewed for the full text based on study population, outcome variable, study location etc. by the authors [IR and $\mathrm{AB}]$. The articles with incomplete data were excluded. Incomplete data covered poorly written results, and absence of desired variables.

The extracted data was maintained in Microsoft excel spreadsheet under column headings: title of the study, journal name, year of study, study design, 1st author's name, study location, nutritional assessment tool used, sample size, numbers in normal nutritional status category, number of malnourished cases (mild/moderate and severe malnutrition).

In this review, the quality of studies was evaluated by using the Newcastle-Ottawa quality assessment form. ${ }^{5}$ This scale is golden standard for the prevalence based meta-analysis. Only studies with quality score greater than $50 \%$ were included in the analysis. The disagreement between the authors with respect to quality control was resolved by formal consensus from all the authors.

\subsection{Statistical analysis}

The software package Comprehensive Meta-analysis version 2.0 and Review Manager (RevMan Cochrane Collaboration 5.4) was used to perform the statistical analysis. The random effect (RE) $\operatorname{model}^{6}$ was used to determine the pooled estimate and subgroup analysis at $95 \%$ confidence interval. The $95 \%$ confidence intervals are reflected in brackets, as applicable, in the results section.

The value of I squared statistic $\left(\mathrm{I}^{2}\right.$ greater than $50 \%$ \& Q test $(\mathrm{p}<$ 0.10 ) was determined to assess the variability due to heterogeneity. The publication bias was evaluated utilizing the funnel plot and eggers regression intercept. The presence of asymmetry reflects publication bias, whereas symmetry reflects absence of publication bias.

The pooled prevalence was reported in "effect size". Subgroup analysis for gender (male and female), patient type (hemodialysis, peritoneal dialysis, non-dialysis \& unspecified dialysis), region (comparison within India), assessment tool used (SGA, MIS, Anthropometry) and geography (comparison of prevalence in India with other countries) were performed

Meta-regression analysis was performed in comprehensive metaanalysis to assess the effect of different covariates (gender, patient type, mean age and geography) in predicting the prevalence of malnutrition at $95 \%$ confidence interval $(\mathrm{p}<0.05)$.

\section{Results}

The electronic search yielded 429 articles from MEDLINE/PubMed and 46 articles from other data sources after finalizing the search strategy [Fig. 1]. A total of 475 articles were screened for the title and 


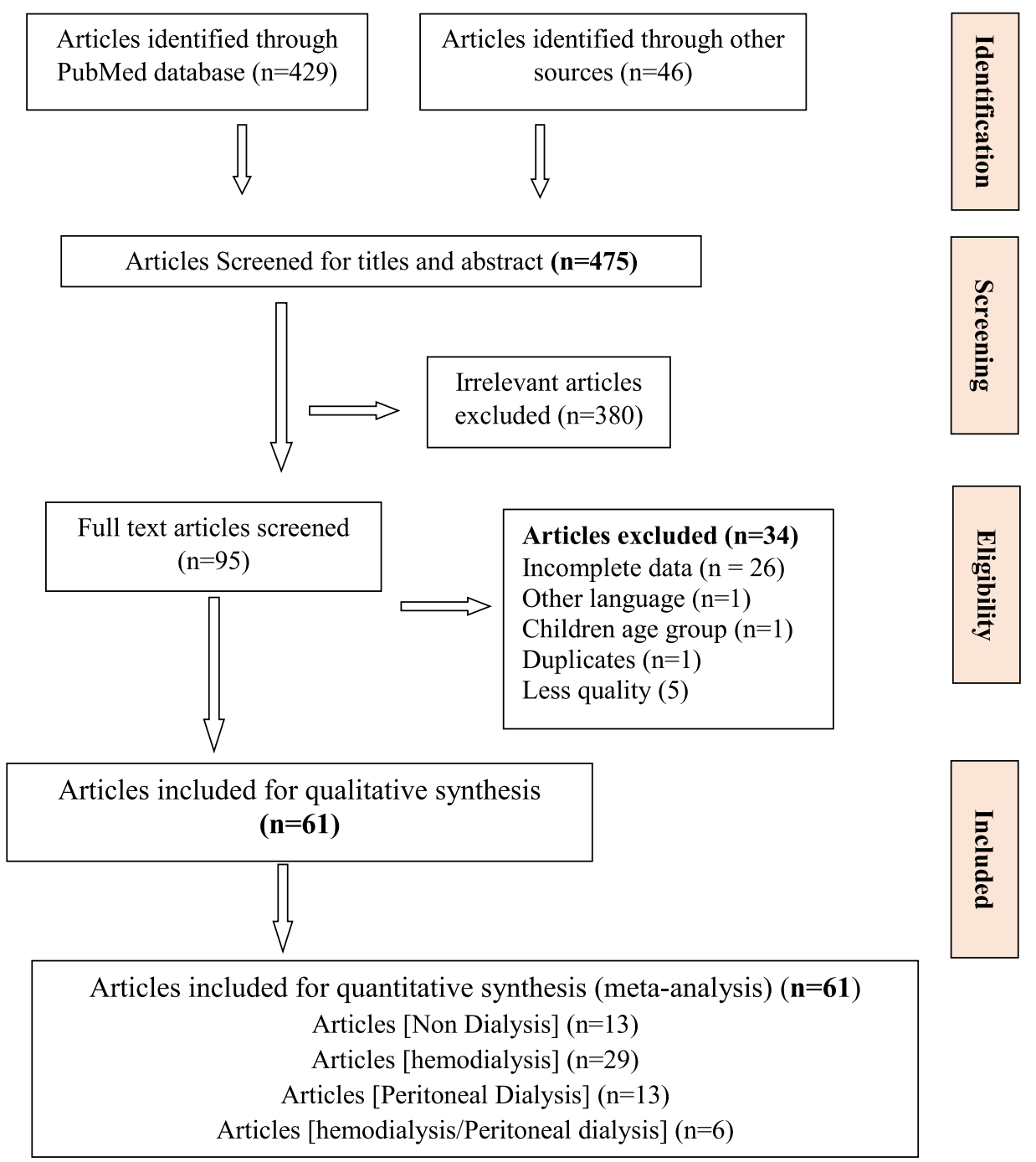

Fig. 1. Systematic review PRISMA flowchart of research articles screened, excluded and included in meta-analysis.

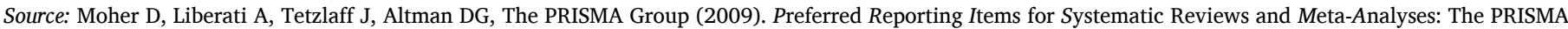
Statement. PLoS Med 6(7):e1000097.

abstract, 380 articles were excluded based on incomplete data, language other than English, children age group, duplicates and less quality. The remaining 95 articles were screened for full text, out of these 34 articles were again left out due to insufficient data, language barrier, duplicates and children age group. A total of 21119 samples from 61 studies were potentially eligible for quantitative analysis. The Supplementary File A represents the relevant details of all studies.

The patients who suffered with chronic kidney disease were evaluated for malnutrition. The study outcomes were reported as effect size, which is the pooled prevalence of malnutrition among chronic kidney disease patients globally along with India based on patient type (nondialysis, hemodialysis, peritoneal-dialysis, \& unspecified dialysis), region (country wise break-up), assessment tool and gender.

\subsection{Global scenario}

The pooled estimate of prevalence was found to be 0.427 with $95 \%$ $\mathrm{CI}$, which means that the mean global prevalence of malnutrition among CKD patients is $42.7 \%$. These studies were sampled from a universe of possible studies defined by certain inclusion/exclusion criteria as outlined in the methodology. ${ }^{7-15,16-24,25-36,37-49,50-67}$ The confidence interval for the prevalence was found to be $0.352-0.506$, which indicates that the mean prevalence in the universe of studies could fall anywhere in the range $35.2 \%-50.6 \%$. The $\mathrm{I}^{2}$ value was found to be 98.58 which shows that $98 \%$ of the variance in observed rates reflect variance in true rates rather than sampling error. The heterogeneity was decreased when sub-group analysis was performed. For the studies reported from India, $\mathrm{I}^{2}$ was found to be $95 \%$. Fig. 2 represents the pooled prevalence of malnutrition among chronic kidney disease patients globally.

\subsection{Subgroup analysis}

Subgroup analysis was performed for multiple covariates [Table 1]. The prevalence breakdown was provided in all sixty-one studies based on patient type. The prevalence of malnutrition in peritoneal dialysis group (thirteen studies) was $45.3 \%$ (95\% CI; 29.5-62-1) higher as compared to hemodialysis group (twenty-nine studies) 43.1\% (95\% CI; 32.2-54.7) followed by non-dialysis group (thirteen studies) $38.5 \%$ (95\% CI; 24.0-55.3). The pooled prevalence of malnutrition in nonspecified dialysis group was found to be $44.8 \%$ (95\% CI; 23.0-68.8).

The geography specific prevalence was examined in fourteen countries with most of the studies reported from India, Brazil, Nigeria, Iran and China etc. [Table 2]. Geographical areas with more than one report were pooled using random effects models. In India, the pooled prevalence of malnutrition among chronic kidney disease patients was found to be $56.7 \%(95 \%$ CI; $42.3-70.1)$ for the nine studies. ${ }^{7-15}$ In 


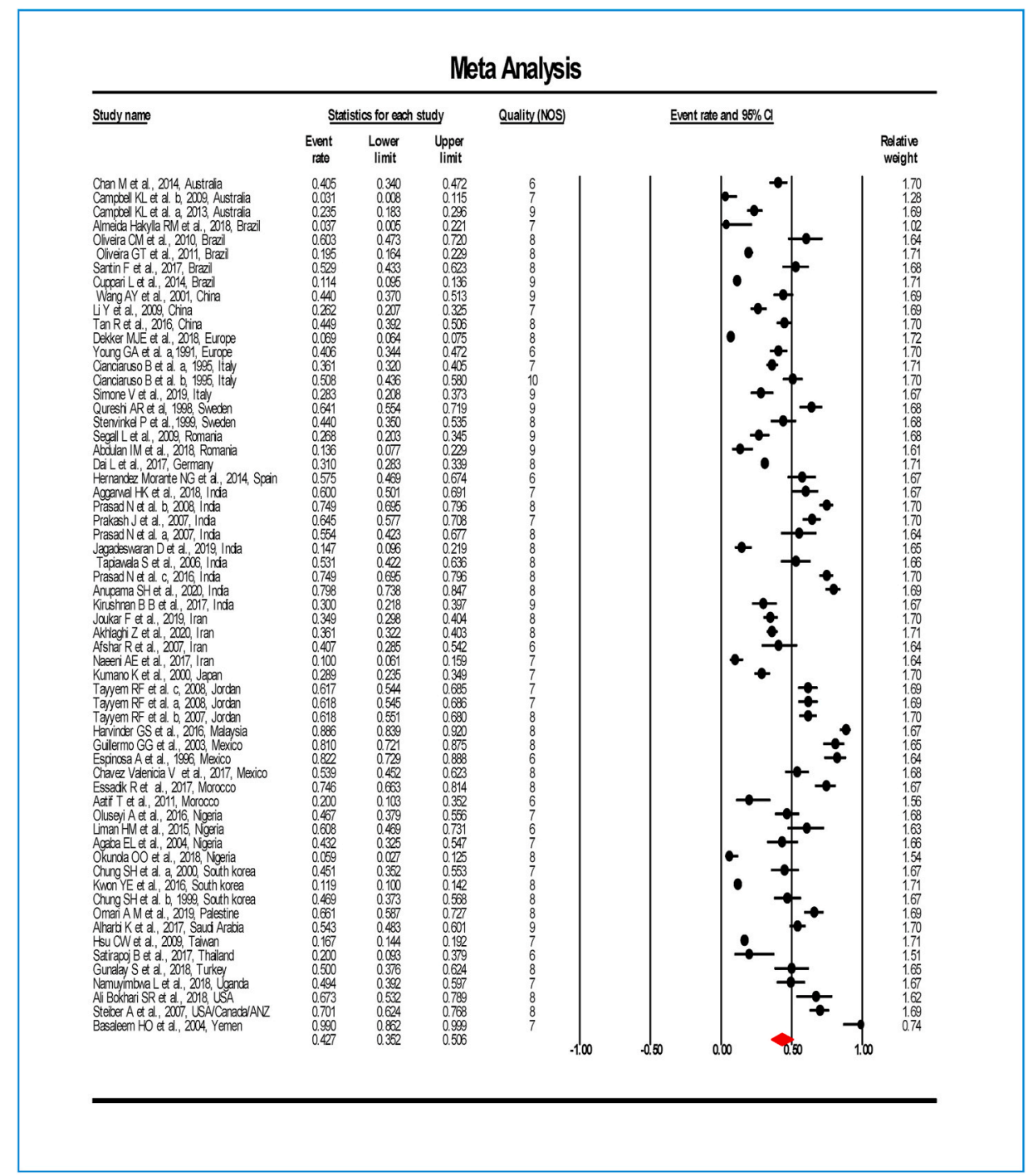

Fig. 2. Global prevalence of malnutrition among chronic kidney disease patients.

(Quality is described by Newcastle Ottawa Scale [NOS] Score, Event rate describes the pooled prevalence, CI as confidence interval, Red box at the bottom indicates total pooled prevalence).

Brazil, ${ }^{39,40,17,41,18}$ it was found to be $26.7 \%$ (95\% CI; 13.8-45.3) and in China, ${ }^{42,43,19}$ it was found to be $37.9 \%$ (95\% CI; 18.5-62.2).

The gender specific prevalence of malnutrition among chronic kidney disease patients was examined in twenty-five studies. ${ }^{16-24,8,11,12,15,25-36}$ The overall gender-specific prevalence was found to be $40.1 \%(28.7-52.7 \%)$. In case of male patients, the pooled prevalence of malnutrition was found to be higher $20.7 \%$ (95\% CI; 14.2-29.3) than female patients $16.4 \%$ (95\% CI; 11.6-22.6).

The breakdown of prevalence analyzed on the basis of "assessment tool" used. The prevalence reported by using subjective global assessment tool ${ }^{36-38,40-43,17,18,45,46,21-25,48,28,11,7,15,9,14,50,51,53,27,28,55,57,30,38}$ ,59,33,60,34,35,63,66,67 was found to be $42.0 \%$, while using Anthropometric measurements ${ }^{20,24,49,10,26,56,29,31,32,62,65,36}$ and Malnutrition inflammation ${ }^{39,47,12,13,52,54,61}$ score the prevalence was found to be $45.8 \%$, and $40.6 \%$.

The univariate and multivariate meta-regression of prevalence and covariates (mean age, patient type, assessment tool used, gender, geography) was performed to find out the effect of covariates on prevalence. The mean population age, \& geography were found to be statistically significantly associated with the prevalence of malnutrition among chronic kidney disease patients $\left(\mathrm{p}<0.032, \mathrm{R}^{2}=0.21 \& \mathrm{p}=\right.$ $0.004, \mathrm{R}^{2}=0.55$ ).

\subsection{Indian scenario}

India comprises highest number of the studies (9) on malnutrition associated with chronic kidney disease across the globe [Fig. 3]. The pooled estimate of prevalence in India was found to be $56.7 \%$ with $95 \%$ CI ranging between $42.4 \%$ and $70.0 \% .^{7-15}$

\subsection{Subgroup analysis}

Subgroup analysis was performed for different patient groups (hemodialysis, peritoneal-dialysis, non-dialysis \& non-specified dialysis) [Table 2]. The pooled prevalence in peritoneal-dialysis group ${ }^{7-9}\{69.2 \%$ ranging from $42.7 \%$ to $87.2 \%$ \} was found to be higher than the hemodialysis group ${ }^{13,14}\{56.8 \%$ ranging from $25.3 \%$ to $83.6 \%\}$, followed by non-dialysis group ${ }^{10-12}\{44.2 \%$ ranging from $20.7 \%$ to $70.6 \%\}$. The non-specified dialysis group ${ }^{15}$ had a mean prevalence of $53.1 \%$ ranging from $14.1 \%$ to $88.6 \%$.

The sex specific prevalence of malnutrition among chronic kidney disease patients was reported in only four studies. The overall pooled prevalence was found to be $50.8 \%$ with a range of $26.9 \%-74.3 \%$. The male patients with chronic kidney disease were (32.7\%) considerably higher affected with malnutrition than female patients $(16.3 \%))^{7,8,12,15}$ 
Table 1

Subgroups analysis based on gender, patient type, geography and assessment tool according to random effect model - a global scenario.

\begin{tabular}{|c|c|c|c|c|c|c|c|}
\hline Sub-groups & $\mathrm{N}$ & Pooled Prevalence [R] & Sample Size & Normal (N) & Mild-Moderate (N) & Severe $(N)$ & Malnutrition $(\mathrm{N})$ \\
\hline \multicolumn{8}{|l|}{ Gender } \\
\hline M & 25 & $20.7 \%(14.2-29.3 \%)$ & 14401 & 11608 & 986 & 1807 & 1539 \\
\hline $\mathbf{F}$ & 25 & $16.4 \%(11.6-22.6 \%)$ & 14401 & 11608 & 986 & 1807 & 1244 \\
\hline \multicolumn{8}{|l|}{ Patient Type } \\
\hline HD & 29 & $43.1 \%(32.2-54.7 \%)$ & 13581 & 10880 & 1071 & 1630 & 2701 \\
\hline PD & 13 & $45.3 \%(29.5-62.1 \%)$ & 2135 & 1034 & 662 & 372 & 1034 \\
\hline ND & 13 & $38.5 \%(24.0-55.3 \%)$ & 2553 & 1730 & 250 & 573 & 823 \\
\hline NSD & 6 & $44.8 \%(23.0-68.8 \%)$ & 2850 & 1951 & 193 & 706 & 899 \\
\hline \multicolumn{8}{|l|}{ Geography } \\
\hline India & 9 & $56.7 \%(42.3-70.1 \%)$ & 1443 & 239 & 480 & 424 & 904 \\
\hline Brazil & 5 & $26.7 \%(13.8-45.3 \%)$ & 1686 & 1378 & 153 & 155 & 308 \\
\hline Nigeria & 4 & $35.0 \%(18.0-56.8 \%)$ & 347 & 222 & 30 & 95 & 125 \\
\hline Iran & 4 & $28.3 \%(14.2-48.6 \%)$ & 1056 & 715 & 86 & 255 & 341 \\
\hline China & 3 & $37.9 \%(18.5-62.2 \%)$ & 690 & 422 & 200 & 68 & 268 \\
\hline Italy & 3 & $38.1 \%(18.5-62.5 \%)$ & 783 & 482 & 28 & 273 & 301 \\
\hline Jordan & 3 & $61.7 \%(37.4-81.3 \%)$ & 575 & 220 & 323 & 32 & 355 \\
\hline Mexico & 3 & $73.7 \%(50.4-88.6 \%)$ & 318 & 94 & 106 & 118 & 224 \\
\hline Australia & 3 & $19.7 \%(7.8-41.6 \%)$ & 488 & 117 & 77 & 60 & 137 \\
\hline South Korea & 3 & $31.2 \%(14.3-55.2 \%)$ & 1135 & 935 & 156 & 44 & 200 \\
\hline Romania & 2 & $19.7 \%(6.5-46.1 \%)$ & 230 & 179 & 40 & 11 & 51 \\
\hline Sweden & 2 & $54.2 \%(25.8-80.2 \%)$ & 237 & 107 & 17 & 113 & 130 \\
\hline Morocco & 2 & $48.2 \%(20.7-76.9 \%)$ & 166 & 64 & 26 & 76 & 102 \\
\hline Europe & 2 & $18.2 \%(6.2-42.7 \%)$ & 8534 & 3835 & 18 & 646 & 664 \\
\hline \multicolumn{8}{|c|}{ Assessment Tool } \\
\hline SGA & 40 & $42.0 \%(33.9-50.7 \%)$ & 9256 & 5852 & 1723 & 1681 & 3404 \\
\hline ANP & 12 & $45.8 \%(30.7-67.8 \%)$ & 10465 & 9138 & 162 & 1165 & 1327 \\
\hline MIS & 7 & $40.6 \%(22.4-61.7 \%)$ & 1046 & 481 & 150 & 415 & 565 \\
\hline
\end{tabular}

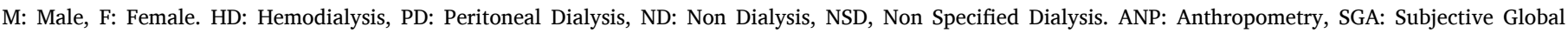
Assessment, MIS: malnutrition Inflammation Score. Column 3 (): Prevalence range - lower and upper limit.

Table 2

Subgroups analysis based on gender, patient type, geography and assessment tool according to random effect model - an Indian scenario.

\begin{tabular}{|c|c|c|c|c|c|c|c|}
\hline Sub-groups & $\mathrm{N}$ & Pooled Prevalence [R] & Sample Size (N) & Normal (N) & Mild-Moderate (N) & Severe $(\mathrm{N})$ & Malnutrition (N) \\
\hline \multicolumn{8}{|l|}{ Gender } \\
\hline M & 4 & $32.7 \%(18.5-51.0)$ & 696 & 291 & 170 & 235 & 280 \\
\hline $\mathrm{F}$ & 4 & $16.3 \%(10.8-23.9)$ & 696 & 291 & 170 & 235 & 125 \\
\hline \multicolumn{8}{|l|}{ Patient Type } \\
\hline HD & 2 & $56.8 \%(25.3-83.6)$ & 308 & 112 & 51 & 145 & 196 \\
\hline PD & 3 & $69.2 \%(42.7-87.2)$ & 622 & 167 & 384 & 71 & 455 \\
\hline ND & 2 & $44.2 \%(20.7-70.6)$ & 432 & 222 & 2 & 208 & 210 \\
\hline \multicolumn{8}{|l|}{ Geography } \\
\hline UP & 3 & $65.6 \%(38.6-85.2)$ & 542 & 168 & 192 & 182 & 374 \\
\hline AP & 2 & $30.8 \%(10.2-63.6)$ & 308 & 112 & 51 & 145 & 196 \\
\hline $\mathrm{TN}$ & 2 & $56.8 \%(25.3-83.6)$ & 210 & 148 & 43 & 19 & 62 \\
\hline \multicolumn{8}{|c|}{ Assessment Tool } \\
\hline SGA & 6 & $59.6 \%(40.0-76.5)$ & 1006 & 347 & 454 & 205 & 659 \\
\hline ANP & 2 & $60.0 \%(17.6-91.3)$ & 337 & 152 & 24 & 161 & 185 \\
\hline
\end{tabular}

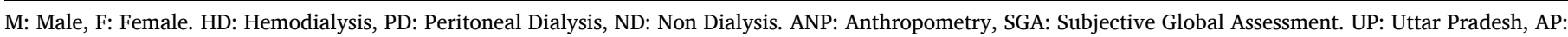
Andhra Pradesh, TN: Tamil Nadu.

Column 3 (): Prevalence range - lower and upper limit.

The breakdown of prevalence was also provided in all the regions where the studies have been conducted. The Utter Pradesh ${ }^{7,8} 65.6 \%$ (38.6-85.2\%) region had a higher pooled prevalence of malnutrition as compared to Chennai ${ }^{13,14} 56.8 \%$ (25.3-83.6\%) followed by Andhra Pradesh $^{12,15} 30.8 \%$ (10.2-63.6\%). The comparison was possible for only regions who have reported more than two studies. The mean prevalence in Rohtak, Haryana ${ }^{10}$ was found to be $60.0 \%$ (18.0-91.1\%) and 74.9\% in Mumbai, Maharashtra ${ }^{9}$ (30.9-95.2\%).

This was further analyzed on the basis of "assessment tool" used. The pooled prevalence reported by using subjective global assessment tool $^{7-12}$ and anthropometric measurements ${ }^{15}$ was found to be $59.6 \%$ and $60.0 \%$. Based on malnutrition inflammation score ${ }^{13,14}$ the prevalence was found to be $45.9 \%$.

\subsection{Quality assessment}

The methodological quality of studies was assessed by Newcastle Ottawa Scale. ${ }^{6}$ All the 61 studies were found to be of good quality ranging from 6 stars to 10 stars (Fig. 2). Sixteen studies scored 7 stars, twenty-seven studies scored 8 stars, nine studies scored 9 stars, eight studies scored 6 stars and only one study scored 10 stars.

\subsection{Heterogeneity and publication bias}

The included sixty-one studies were assessed for heterogeneity and publication bias. Accordingly, the analysis showed a substantial heterogeneity of $Q$ test $(\mathrm{p}<0.001)$ and $\mathrm{I}^{2}$ statistic $\left(\mathrm{I}^{2}=98.5 \%\right)$. The funnel plot for publication bias showed no symmetry while the Egger's test for a 


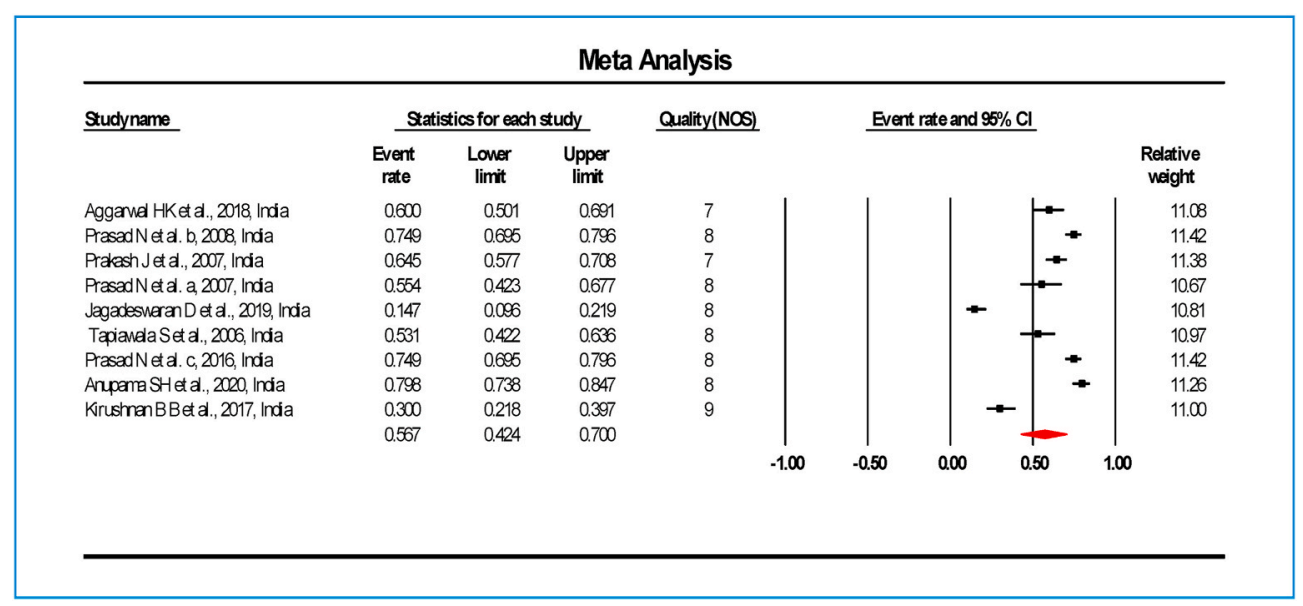

Fig. 3. Prevalence of malnutrition among chronic kidney disease patients in India.

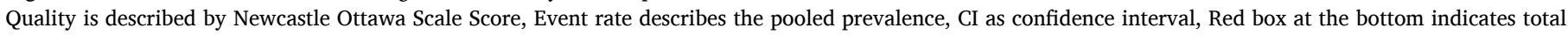
pooled prevalence).

regression intercept gave a p-value of less than 0.001 verifying the presence of bias. There was no change in heterogeneity while assessing for the subgroups like gender $\left(\mathrm{I}^{2}=99.0 \%\right)$, and geography $\left(\mathrm{I}^{2}=98.6 \%\right)$, though it has been found to be slightly increased.

\subsection{Sensitivity analysis}

Sensitivity analysis of the sixty-one studies was done to test the effect of each study on the pooled result by excluding each study step by step (i.e based on sixty studies) and the results showed that one study (Marjike et al., 2018) was relatively the prime determinants higher heterogeneity. The $\mathrm{I}^{2}$ statistic changes from $\mathrm{I}^{2}=98.5 \%$ to $\mathrm{I}^{2}=97.2 \%$ after removing Marjike et al. study. There was no change in heterogeneity while performing sensitivity analysis for other studies.

\subsection{Meta regression}

The Univariate meta-regressions of malnutrition prevalence and covariates (mean age, \& geography) was undertaken to determine the effect of covariates on prevalence. The mean population age, given in 57 of 61 populations was significantly associated $\left(\mathrm{p}=0.03, \mathrm{R}^{2}=0.21\right)$ as was geography ( $\mathrm{p}<0.001, \mathrm{R}^{2}=0.55$ ), with the prevalence of malnutrition among chronic kidney disease patients. No significant association was observed for gender and patient type. Here $\mathrm{R}^{2}$ is used to quantify the proportion of variance likely to be explained by different kinds of covariates or interventions. This index $\left(\mathrm{R}^{2}\right)$ is intuitive as it can be interpreted as a ratio, with a range of $0-1$, or of $0 \%-100 \%$.

\section{Discussion}

This meta-analysis comprises 61 observational studies and provides estimated pooled prevalence of malnutrition associated with chronic kidney disease in India and other countries. Globally, India occupies the highest share of prevalence studies $14.75 \%$ followed by Brazil $8.19 \%$. The geographical stratification of results revealed that developing areas where economies are growing such as Mexico (73.7\%), Jordan (61.7\%), and India (56.7\%) had higher rates of CKD associated malnutrition prevalence in comparison to areas which are developed such as Australia (19.7\%), Europe (18.2\%) etc. In India, the prevalence of malnutrition was also higher as compared to its neighboring countries like China (37.9\%), \& Iran (28.3\%), even it was higher all across Asia. The cultural, religious and ecological diversity of India poses a challenge to evaluate nutritional status among different patient populations. This wide variation may be due to varying number of studies conducted and reported.
Also, the existing literature stated that the different socio-economic status, level of education and poor approach to medical facility may be the possible reason. However, the exact cause of malnutrition associated with chronic kidney disease are complex and multifactorial.

This review also reflects that a significant variation of prevalence exists on the basis of patient type such as patients on hemodialysis, peritoneal dialysis and non-dialysis. In case of non-dialysis chronic kidney patients, Prasad et al. from India have reported that the high prevalence could be due to late medical attention, severe uremic symptoms with poor appetite and decrease in dietary food intake. ${ }^{11}$ Prakash et al. had reported elevated serum total iron binding capacity (due to iron deficiency \& low serum transferrin level) in patients with malnutrition but without appearance of signs and symptoms. They have also reported increase in serum triglyceride levels in chronic kidney disease patients with malnutrition, which can further heighten the already increase cardiovascular risk in chronic kidney disease patients. ${ }^{32}$ The findings related to causes of malnutrition associated with chronic kidney disease reported by Agaba et al. from Nigeria were in consonance with the findings of Prakash et al.

In case of hemodialysis patients, Anupama et al. (after stratifying the severity of malnutrition according to the stages of chronic kidney disease) have found that malnutrition is higher in progressive stages along with patients having low-socio economic status. Ramalakshmi et al. reported carnitine deficiency among $64.3 \%$ dialysis population in India. ${ }^{68}$

The peritoneal dialysis patients are known to have decreased appetite and early satiety. The findings of Oreopoulos et al. and Von Baeyer et al. confirm that uremia, absorption of glucose and abdominal distension by the dialysate fluid are the possible causes for the loss of appetite. ${ }^{69}$

Around $40 \%$ of the studies reported gender specific prevalence of malnutrition among CKD patients and the results highlighted considerably higher prevalence among male patients. However, these findings can't answer why this may occur. We can only speculate that these findings may be partially explained by selection bias inherent within the studies due to a different age demographic for the two sexes. Alternatively, it may be due to complex factors in the disease pathology that are not captured within the studies.

This meta-analysis also provided the prevalence of malnutrition associated with CKD on the basis of different assessment tool available. Globally, the pooled estimate of malnutrition prevalence was found to be almost in the same range such as $42.0 \%$ (SGA), 45.8 (ANP) and $40.6 \%$ (MIS). However, in Indian scenario the subgroup analysis based on assessment tools was not possible for all the tools reported in this study. 
The pooled estimate of prevalence was only possible for SGA $(59.6 \%)$ and ANP (60.0\%) which has been found to be quite similar. Only one study has reported prevalence by using malnutrition inflammation score (MIS).

Our principal finding is that the overall pooled prevalence of malnutrition associated with chronic kidney disease globally falls anywhere in between 35.2 and 50.6\%. As chronic kidney disease progresses to higher stages the patient needs to titrate the diet and daily food intake because of compromised kidney's filtration ability. So it is quite apparent, malnutrition among chronic kidney disease patients is mostly because of treatment forced restrictions in the diet and insufficient food intake (due to poor appetite).

This meta-analysis of malnutrition prevalence in patients with chronic kidney disease provides more precise evidence-based estimates than previously reported, which credibly illustrate the commonness of this complication in patients with hemodialysis, peritoneal dialysis and non-dialysis. Our results also explored that the prevalence of malnutrition is insufficiently studied in some scenarios, such as CKD stages, pediatric CKD population, \& kidney transplant recipients.

\subsection{Strength \& limitations}

The consideration of validated tools like subjective global assessment tool and malnutrition inflammation score could preserve the appropriateness of this review. This is the first country wide estimate of the prevalence of malnutrition among chronic kidney disease patients in India. The subgroup analysis shows differential prevalence based on gender, patient type, and geography.

The pooled prevalence was estimated from cross sectional, cohort and case control studies. The variation in the study design is a limitation beyond the control of the researchers. The random effect model prevalence estimates and New-castle Ottawa scale for quality assessment can be used with caution.

\section{Conclusions}

In conclusion, the study findings confirms that India occupies the highest share of prevalence studies, globally. In India, the pooled prevalence of malnutrition among chronic kidney disease patients was lower as compared to Mexico and Jordan; while it was considerably high as compared to Brazil, China, Iran etc. The male patients were considerably higher affected with malnutrition than the female patients.

Given the high prevalence of malnutrition among CKD patients, evaluation of interventions for malnutrition with patient centered outcomes are warranted.

\section{Future research}

The existing literature suggests that, malnutrition is poorly characterized among CKD stages, which offers a window for further research in this domain. Also large-scale interventional studies using validated tools should be performed to assess the effect of nutritional uptake programs on chronic kidney disease patient's nutritional status. Additionally, to further address the underlying mechanisms of malnutrition, there is an urgent need to map its risk factors.

\section{Declaration of competing interest}

The authors declare no conflict of interest exists.

\section{Acknowledgements}

The authors like to thank National Institute of Pharmaceutical Education and Research for providing access to comprehensive metaanalysis package to perform statistical analysis.

\section{Appendix A. Supplementary data}

Supplementary data to this article can be found online at https://doi. org/10.1016/j.cegh.2021.100855.

\section{Funding source}

This research did not receive any specific grant from funding agencies in the public, commercial, or not-for-profit sectors.

\section{References}

1 Pupim LB, Cuppari L, Ikizler TA. Nutrition and metabolism in kidney disease. Semin Nephrol. 2006;26(2):134-157.

2 Feroze U, Noori N, Kovesdy CP, et al. Quality-of-life and mortality in hemodialysis patients: roles of race and nutritional status. Clin J Am Soc Nephrol. 2011 May;6(5): 1100-1111.

3 Avram MM, Goldwasser P, Erroa M, Fein PA. Predictors of survival in continuous ambulatory peritoneal dialysis patients: the importance of prealbumin and other nutritional and metabolic markers. Am J Kidney Dis. 1994 Jan;23(1):91-98.

4 Stroup DF, Berlin JA, Morton SC, et al. Meta-analysis of observational studies in Epidemiology: a proposal for reporting. J Am Med Assoc. 2000;283(15):2008-2012.

5 Ma LL, Wang YY, Yang ZH, Huang D, Weng H, Zeng XT. Methodological quality (risk of bias) assessment tools for primary and secondary medical studies: what are they and which is better? Military Med Res. 2020;7(7):2-11.

6 Jackson D, Law M, Barrett JK, et al. Extending DerSimonian and Laird's methodology to perform network meta-analyses with random inconsistency effects. Stat Med. 2016 Mar;35(6):819-839.

7 Prasad N, Gupta A, Sharma RK, Sinha A, Kumar R. Impact of nutritional status on peritonitis in CAPD patients. Perit Dial Int. 2007 Jan-Feb;27(1):42-47.

8 Prasad N, Gupta A, Sinha A, Sharma RK, Kumar A, Kumar R. Changes in nutritional status on follow-up of an incident cohort of continuous ambulatory peritoneal dialysis patients. J Ren Nutr. 2008 Mar;18(2):195-201.

9 Prasad N, Sinha A, Gupta A, et al. Validity of nutrition risk index as a malnutrition screening tool compared with subjective global assessment in end-stage renal disease patients on peritoneal dialysis. Indian J Nephrol. 2016 Jan-Feb;26(1):27-32.

10 Aggarwal HK, Jain D, Chauda R, Bhatia S, Sehgal R. Assessment of malnutrition inflammation score in different stages of chronic kidney disease. Pril (Makedon Akad Nauk Umet Odd Med Nauki). 2018 Dec 1;39(2-3):51-61.

11 Prakash J, Raja R, Mishra RN, et al. High prevalence of malnutrition and inflammation in undialyzed patients with chronic renal failure in developing countries: a single center experience from eastern India. Ren Fail. 2007;29(7): 811-816.

12 Jagadeswaran D, Indhumathi E, Hemamalini AJ, Sivakumar V, Soundararajan P, Jayakumar M. Inflammation and nutritional status assessment by malnutrition inflammation score and its outcome in pre-dialysis chronic kidney disease patients. Clin Nutr. 2019 Feb;38(1):341-347.

13 Anupama SH, Abraham G, Alex M, et al. A multicenter study of malnutrition status in chronic kidney disease stages I-V-D from different socioeconomic groups. Saudi J Kidney Dis Transpl. 2020;31:614-623.

14 Kirushnan BB, Subba Rao B, Annigeri R, et al. Impact of malnutrition, inflammation, and atherosclerosis on the outcome in hemodialysis patients. Indian J Nephrol. 2017 Jul-Aug;27(4):277-283.

15 Tapiawala S, Vora H, Patel Z, Badve S, Shah B. Subjective global assessment of nutritional status of patients with chronic renal insufficiency and end stage renal disease on dialysis. J Assoc Phys India. 2006 Dec;54:923-926.

16 Campbell KL, Bauer JD, Ikehiro A, Johnson DW. Role of nutrition impact symptoms in predicting nutritional status and clinical outcome in hemodialysis patients: a potential screening tool. J Ren Nutr. 2013 Jul;23(4):302-307.

17 Oliveira GT, Andrade EI, Acurcio Fde A, Cherchiglia ML, Correia MI. Nutritional assessment of patients undergoing hemodialysis at dialysis centers in Belo Horizonte, MG, Brazil. Rev Assoc Med Bras. 1992;58(2):240-247, 2012 Mar-Apr.

18 Cuppari L, Meireles MS, Ramos CI, Kamimura MA. Subjective global assessment for the diagnosis of protein-energy wasting in nondialysis-dependent chronic kidney disease patients. J Ren Nutr. 2014 Nov;24(6):385-389.

19 Tan R, Long J, Fang S, et al. Nutritional Risk Screening in patients with chronic kidney disease. Asia Pac J Clin Nutr. 2016;25(2):249-256.

20 Dekker MJE, Konings C, Canaud B, et al. Interactions between malnutrition, inflammation, and fluid overload and their associations with survival in prevalent hemodialysis patients. J Ren Nutr. 2018 Nov;28(6):435-444.

21 Qureshi AR, Alvestrand A, Danielsson A, et al. Factors predicting malnutrition in hemodialysis patients: a cross-sectional study. Kidney Int. 1998 Mar;53(3):773-782.

22 Stenvinkel P, Heimbürger O, Paultre F, et al. Strong association between malnutrition, inflammation, and atherosclerosis in chronic renal failure. Kidney Int. 1999 May;55(5):1899-1911.

23 Abdulan IM, Onofriescu M, Stefaniu R, et al. The predictive value of malnutrition for functional and cognitive status in elderly hemodialysis patients. Int Urol Nephrol. 2019 Jan;51(1):155-162.

24 Dai L, Mukai H, Lindholm B, et al. Clinical global assessment of nutritional status as predictor of mortality in chronic kidney disease patients. PloS One. 2017 Dec 6;12 (12), e0186659. 
25 Akhlaghi Z, Sharifipour F, Nematy M, et al. Assessment of nutritional status in maintenance hemodialysis patients: a multicenter cross-sectional study in Iran. Semin Dial. 2020 Oct 14.

26 Kumano K, Kawaguchi Y. Multicenter cross-sectional study for dialysis dose and physician's subjective judgment in Japanese peritoneal dialysis patients. Group for the Water and Electrocyte Balance Study in CAPD. Am J Kidney Dis. 2000 Mar;35(3): 515-525.

27 Tayyem RF, Mrayyan MT. Assessing the prevalence of malnutrition in chronic kidney disease patients in Jordan. J Ren Nutr. 2008 Mar;18(2):202-209.

28 Tayyem RF, Mrayyan MT. Malnutrition, and anthropometric and biochemical abnormalities in end-stage renal disease patients. Saudi Med J. 2007 Oct;28(10): 1575-1581.

29 Chávez Valencia V, Mejía Rodríguez O, Viveros Sandoval ME, et al. Prevalence of malnutrition-inflammation complex syndrome and its correlation with thyroid hormones in chronic haemodialysis patients. Nefrologia. 2018 Jan-Feb;38(1):57-63.

30 Aatif T, Hassani K, Alayoud A, et al. Parameters to assess nutritional status in a Moroccan hemodialysis cohort. Arab J Nephrol. Transplant. 2013 May;6(2):89-97.

31 Oluseyi A, Enajite O. Malnutrition in pre-dialysis chronic kidney disease patients in a teaching hospital in Southern Nigeria. Afr Health Sci. 2016 Mar;16(1):234-241.

32 Agaba EI, Agaba PA. Prevalence of malnutrition in Nigerians with chronic renal failure. Int Urol Nephrol. 2004;36(1):89-93.

33 Chung SH, Lindholm B, Lee HB. Influence of initial nutritional status on continuous ambulatory peritoneal dialysis patient survival. Perit Dial Int. 2000 Jan-Feb;20(1): 19-26.

34 Chung SH, Na MH, Lee SH, Park SJ, Chu WS, Lee HB. Nutritional status of Korean peritoneal dialysis patients. Perit Dial Int. 1999;19(Suppl 2):S517-S522.

35 Alharbi K, Enrione EB. Malnutrition is prevalent among hemodialysis patients in Jeddah, Saudi Arabia. Saudi J Kidney Dis Transpl. 2012 May;23(3):598-608.

36 Basaleem HO, Alwan SM, Ahmed AA, Al-Sakkaf KA. Assessment of the nutritional status of end-stage renal disease patients on maintenance hemodialysis. Saudi $J$ Kidney Dis Transpl. 2004 Oct-Dec;15(4):455-462.

37 Chan M, Kelly J, Batterham M, Tapsell L. A high prevalence of abnormal nutrition parameters found in predialysis end-stage kidney disease: is it a result of uremia or poor eating habits? J Ren Nutr. 2014 Sep;24(5):292-302.

38 Campbell KL, Ash S, Zabel R, McFarlane C, Juffs P, Bauer JD. Implementation of standardized nutrition guidelines by renal dietitians is associated with improved nutrition status. J Ren Nutr. 2009 Mar;19(2):136-144.

39 Almeida HRM, Santos EMC, Dourado K, Mota C, Peixoto R. Malnutrition associated with inflammation in the chronic renal patient on hemodialysis. Rev Assoc Med Bras. 1992;64(9):837-844, 2018 Sep.

40 Oliveira CM, Kubrusly M, Mota RS, Silva CA, Oliveira VN. Malnutrition in chronic kidney failure: what is the best diagnostic method to assess? J Bras Nefrol. 2010 Mar; 32(1):55-68.

41 Santin F, Rodrigues J, Brito FB, Avesani CM. Performance of subjective global assessment and malnutrition inflammation score for monitoring the nutritional status of older adults on hemodialysis. Clin Nutr. 2018 Apr;37(2):604-611.

42 Wang AY, Sea MM, Ip R, et al. Independent effects of residual renal function and dialysis adequacy on actual dietary protein, calorie, and other nutrient intake in patients on continuous ambulatory peritoneal dialysis. J Am Soc Nephrol. 2001 Nov; 12(11):2450-2457.

43 Li Y, Dong J, Zuo L. Is subjective global assessment a good index of nutrition in peritoneal dialysis patients with gastrointestinal symptoms? Perit Dial Int. 2009 Feb; 29(Suppl 2):S78-S82.

44 Young GA, Kopple JD, Lindholm B, et al. Nutritional assessment of continuous ambulatory peritoneal dialysis patients: an international study. Am J Kidney Dis. 1991 Apr;17(4):462-471.

45 Cianciaruso B, Brunori G, Kopple JD, et al. Cross-sectional comparison of malnutrition in continuous ambulatory peritoneal dialysis and hemodialysis patients. Am J Kidney Dis. 1995 Sep;26(3):475-486.

46 Cianciaruso B, Brunori G, Traverso G, et al. Nutritional status in the elderly patient with uraemia. Nephrol Dial Transplant. 1995;10(6):65-68.

47 Simone V, Lara C, Silvia A, Camilla F, Matteo C, Piergiorgio M. Sarcopenia is associated with malnutrition but not with systemic inflammation in older persons with advanced CKD. Nutrients. 2019 Jun;11(6):1378.
48 Segall L, Mardare NG, Ungureanu S, et al. Nutritional status evaluation and survival in haemodialysis patients in one centre from Romania. Nephrol Dial Transplant. 2009; 24:2536-2540.

49 Hernández Morante JJ, Sánchez-Villazala A, Cutillas RC, Fuentes MC. Effectiveness of a nutrition education program for the prevention and treatment of malnutrition in end-stage renal disease. J Ren Nutr. 2014 Jan;24(1):42-49.

50 Joukar F, Moradi Z, Hasavari F, Atrkar Roushan Z, Sedighi A, Asgharnezhad M. Malnutrition in hemodialysis patients and predicting factors: a cross-sectional study. Nephro-Urol Mon. 2019;11(3), e86586.

51 Afshar R, Sanavi S, Izadi-Khah A. Assessment of nutritional status in patients undergoing maintenance hemodialysis: a single-center study from Iran. Saudi $J$ Kidney Dis Transpl. 2007 Sep;18(3):397-404.

52 Naeeni AE, Poostiyan N, Teimouri Z, et al. Assessment of severity of malnutrition in peritoneal dialysis patients via malnutrition: inflammatory score. Adv Biomed Res. 2017;6:128.

53 Tayyem RF, Mrayyan MT, Heath DD, Bawadi HA. Assessment of nutritional status among ESRD patients in Jordanian hospitals. J Ren Nutr. 2008 May;18(3):281-287.

54 Harvinder GS, Swee WC, Karupaiah T, et al. Dialysis Malnutrition and Malnutrition Inflammation Scores: screening tools for prediction of dialysis-related protein-energy wasting in Malaysia. Asia Pac J Clin Nutr. 2016;25(1):26-33.

55 Guillermo GG, Maria Guadalupe NM, Gregorio TO. Prevalence of malnutrition in low-income Mexican CAPD patients. Perit Dial Int. Sep 2003;23(5):499-508.

56 Espinosa A, Cueto-Manzano AM, Velazquez-Alva C, et al. Prevalence of malnutrition in Mexican CAPD diabetic and nondiabetic patients. Adv Perit Dial Conf. 1996;12: 302-306.

57 Essadik R, Msaad R, Lebrazi H, et al. Assessing the prevalence of protein-energy wasting in haemodialysis patients: a cross-sectional monocentric study. Néphrol Thérapeutique. 2017 Dec;13(7):537-543.

58 Liman HM, Anteyi EA, Oviasu E. Prevalence of malnutrition in chronic kidney disease: a study of patients in a tertiary Hospital in Nigeria. Sahel Med J. 2015;18: S8-S11.

59 Okunola OO, Erohubie CO, Arogundade FA, et al. The prevalence and pattern of malnutrition in pre-dialytic chronic kidney disease patients at a tertiary care facility in Nigeria. W Afr J Med. 2018 Sep-Dec;35(3):180-188.

60 Kwon YE, Kee YK, Yoon CY, et al. Change of nutritional status assessed using subjective global assessment is associated with all-cause mortality in incident dialysis patients. Medicine (Baltim). 2016 Feb;95(7), e2714.

61 Omari AM, Omari LS, Dagash HH, Sweileh WM, Natour N, Zyoud SH. Assessment of nutritional status in the maintenance of haemodialysis patients: a cross-sectional study from Palestine. BMC Nephrol. 2019;20:92.

62 Hsu CW, Lin JL, Lin-Tan DT, et al. Association of environmental cadmium exposure with inflammation and malnutrition in maintenance haemodialysis patients. Nephrol Dial Transplant. 2009 Apr;24(4):1282-1288.

63 Satirapoj B, Limwannata P, Kleebchaiyaphum C, et al. Nutritional status among peritoneal dialysis patients after oral supplement with ONCE dialyze formula. Int $J$ Nephrol Renovascular Dis. 2017 Jun 13;10:145-151.

64 Günalay S, Öztürk YK, Akar H, Mergen H. The relationship between malnutrition and quality of life in haemodialysis and peritoneal dialysis patients. Rev Assoc Med Bras. 1992;64(9):845-852, 2018 Sep.

65 Namuyimbwa L, Atuheire C, Okullo J, Kalyesubula R. Prevalence and associated factors of protein- energy wasting among patients with chronic kidney disease at Mulago hospital, Kampala-Uganda: a cross-sectional study. BMC Nephrol. 2018 Jun 14;19(1):139.

66 Ali Bokhari SR, Faizan Ali MA, Khalid SA, et al. The development of malnutrition is not dependent on its traditional contributing factors in patients on maintenance hemodialysis in developing countries. Saudi J Kidney Dis Transpl. 2018 Mar-Apr;29 (2):351-360.

67 Steiber AL, Kalantar-Zadeh K, Secker D, McCarthy M, Sehgal A, McCann L. Multicenter study of the validity and reliability of subjective global assessment in the hemodialysis population. J Ren Nutr. 2007 Sep;17(5):336-342.

68 Ramalakshmi S, Baben B, Ashok BS, Jayanthi V, Leslie N, Abraham G. Association of carnitine deficiency in Indian continuous ambulatory peritoneal dialysis patients with anemia, erythropoietin use, residual renal function, and diabetes mellitus. Perit Dial Int. 2007;27(2):S235-S238.

69 Von Baeyer H, Gahl GM, Riedinger H, et al. Adaptation of CAPD patients to the continuous peritoneal energy uptake. Kidney Int. 1983 Jan;23(1):29-34. 